\title{
ROLE OF PATCH TEST IN CONTACT DERMATITIS: A CROSS-SECTIONAL STUDY: JAIPUR
}

Shifa Yadav ${ }^{1}$, Dinesh Mathur², Manisha Nijhawan³, Savita Agrawal ${ }^{4}$, Aakansha Singh ${ }^{5}$, Vibhor Goyal 6 , Shilpa Soni ${ }^{7}$, Rakesh Jangra ${ }^{8}$

\section{HOW TO CITE THIS ARTICLE:}

Shifa Yadav, Dinesh Mathur, Manisha Nijhawan, Savita Agrawal, Aakansha Singh, Vibhor Goyal, Shilpa Soni, Rakesh Jangra. "Role of Patch Test in Contact Dermatitis: A Cross-Sectional Study: Jaipur". Journal of Evolution of Medical and Dental Sciences 2014; Vol. 3, Issue 44, September 15; Page: 10840-10845,

DOI: $10.14260 /$ jemds/2014/3413

ABSTRACT: Contact dermatitis is an inflammatory response of the skin to an exogenous substance (irritant and/or allergen). It can be classified as follows: Irritant contact dermatitis, Allergic contact dermatitis, Photo contact, phototoxic dermatitis, Immediate contact reactions, Non-eczematous reactions Only the superficial regions of the skin are affected in contact dermatitis. Inflammation of the affected tissue is present in the epidermis and the outer dermis. ${ }^{1}$ Unlike contact urticaria, in which a rash appears within minutes of exposure and fades away within minutes to hours, contact dermatitis takes days to appear. In our study we have shown the list of most common allergens found positive in our patients. STUDY DESIGN: It was a cross sectional study. METHOD: Study was conducted in mahatma Gandhi hospital Jaipur over a period of 4 months of duration. Patients suspected to have contact dermatitis were subjected to patch testing. Based on the history clinical signs and symptoms. Total 42 patients were short listed in 4 months of duration. RESULT: Our study showed that the most common allergen showing patch test positivity in both males and females were nickel sulphate, cophony, and cobalt sulphate. Patients showed significant improvement in their dermatitis after avoidance of the offending agent. CONCLUSION: Patch test is the method of choice and the "gold standard" in the detection of contact allergy and allergic contact dermatitis.

INTRODUCTION: Contact dermatitis is an inflammatory response of the skin to an exogenous substance (irritant and/or allergen). It can be classified as follows:

- Irritant contact dermatitis

- Allergic contact dermatitis

- Photo contact, phototoxic dermatitis
- Immediate contact reactions

- Non-eczematous reactions

Only the superficial regions of the skin are affected in contact dermatitis. Inflammation of the affected tissue is present in the epidermis and the outer dermis ${ }^{1}$. Unlike contact urticaria, in which a rash appears within minutes of exposure and fades away within minutes to hours, contact dermatitis takes days to appear. In our study we have shown the list of most common allergens found positive in our patients.

STUDY DESIGN: It was a cross sectional study

METHOD: Study was conducted in Mahatma Gandhi hospital Jaipur over a period of 4 months of duration. Patients suspected to have contact dermatitis were subjected to patch testing. Based on the history clinical signs and symptoms. Total 42 patients were short listed in 4 months of duration. 
Patients were asked to avoid oral prednisone or other immunosuppressive medications for at least a week prior to testing as this may suppress positive reactions. Patients were called after two days for the interpretation of the result. The result for each test site is recorded on the basis of ICDRG (International Contact Dermatitis Research Group) grading of patch test (Figure 1).

- $\quad$ Negative $(-)$

- Equivocal / uncertain (+/-)

- $\quad$ Strong positive $(++)$
- Irritant reaction (IR)

- Weak positive $(+)$

- Extreme reaction $(+++)$

Irritant reactions include miliaria (sweat rash), follicular pustules, and burn-like reactions. Uncertain reactions refer to a pink area under the test chamber. Weak positives are slightly elevated pink or red plaques, usually with mild vesiculation. Strong positives are 'papulovesicles' and extreme reactions have spreading redness, severe itching, and blisters or ulcers.

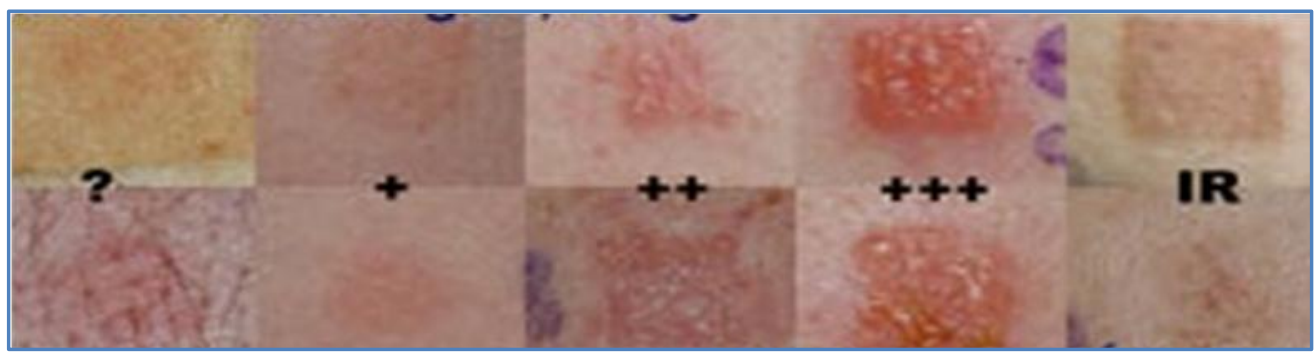

Fig. 1: Notation of positive patch test results according to ICDRG

\section{MATERIAL:}

- Patch test strips

- Standard battery of allergens which consist of 20 allergens which are named as follow:
1. Wool alcohol
2. Formaldehyde
3. Mercaptobenzene
4. Potassium dichromate
5. Nickel sulphate
6. Cobalt sulphate
7. Colphony
8. Parabenes
9. Paraphenyldiamine
10. Parthenium
11. Neomycin
12. Benzocaine
13. Cholrocresol
14. Fragnance
15. Thiuram mix
16. Nitrofurozon
17. Black rubber
18. Balsum of peru
19. Epoxy resin
20. Vaseline

\section{RESULT:}

- Patients' age group was from 20-60 years.

- Out of 42 patients 10 were farmers 3 male and 7 females (23\%), 10 were housewife's (35\%), 7 were businessman, 3 were electrician, 2 were painters, 3 were students, 7 were students. 
ORIGINAL ARTICLE

\begin{tabular}{|c|c|c|c|c|}
\hline Name of allergen & $\begin{array}{c}\text { Total male } \\
\text { positive }\end{array}$ & $\%$ & $\begin{array}{c}\text { Total female } \\
\text { positive }\end{array}$ & $\%$ \\
\hline Nickel sulphate & 6 & $14.2 \%$ & 6 & $14.2 \%$ \\
\hline colphony & 6 & $14.2 \%$ & 6 & $14.2 \%$ \\
\hline Cobalt sulphate & 4 & $9.5 \%$ & 2 & $4.7 \%$ \\
\hline Potassium dichromate & 5 & $11.9 \%$ & 1 & $2.3 \%$ \\
\hline parthenium & 2 & $4.7 \%$ & 7 & $16.6 \%$ \\
\hline paraphenyldiamine & 2 & $4.7 \%$ & 4 & $9.5 \%$ \\
\hline chlorocresol & 3 & $7.1 \%$ & 4 & $9.5 \%$ \\
\hline Thiuram mix & 2 & $4.7 \%$ & 4 & $9.5 \%$ \\
\hline fragnance & 2 & $4.7 \%$ & 2 & $4.7 \%$ \\
\hline formaldehyde & 2 & $4.7 \%$ & 1 & $2.3 \%$ \\
\hline mercaptobenzene & 2 & $4.7 \%$ & 1 & $2.3 \%$ \\
\hline nitrofurozon & 2 & $4.7 \%$ & 0 & $0 \%$ \\
\hline neomycin & 1 & $2.3 \%$ & 0 & $0 \%$ \\
\hline benzocaine & 2 & $4.7 \%$ & 0 & $0 \%$ \\
\hline Wool alcohol & 1 & $2.3 \%$ & 0 & $0 \%$ \\
\hline Black rubber & 3 & $7.1 \%$ & 0 & $0 \%$ \\
\hline Balsum of peru & 0 & $0 \%$ & 1 & $2.3 \%$ \\
\hline Epoxy resin & 1 & $2.3 \%$ & 0 & $0 \%$ \\
\hline parabenes & 0 & $0 \%$ & 1 & $2.3 \%$ \\
\hline Black rubber & 3 & $7.1 \%$ & 0 & $0 \%$ \\
\hline vaseline & 0 & $0 \%$ & 0 & $0 \%$ \\
\hline
\end{tabular}

Our study showed that the most common allergen showing patch test positivity in both males and females were nickel sulphate, cophony, and cobalt sulphate. In females the allergen showing highest positivity was as follows in decreasing order paraphenyldiamine, parthenium, cholrocresol and thiurammix. In males the allergens showing highest positivity were as follows: Nickel sulphate, colphony, potassium dichromate, cobaltsulphate, cholrocresol, blackrubber. Allergens which showed least positivity in both males and females were wool alcohol, formaldehyde, mercaptobenzene, fragrance. Allergens which did not came positive in any male were parabenes, balsum of peru, Allergens which did not came positive in any female were wool alcohol, neomycin, benzocaine, nitrofurozon, blackrubber, epoxy resin 
Out of 42 patients 14 showed strongly positive reaction and 16 showed weakly positive reaction 5 patients showed equivocal response rest 7 patients showed extreme reaction. Out of these 30 patients who showed strongly positive reaction 25 patients showed improvement in their eczema after removing the offending agent. Out of 15 patients who showed weak positive reaction 12 of them showed improvement on removing the offending agent. Out of 20 patients who showed equivocal response only 7 patients showed improvement on removing the offending agent. 5 patients who showed extreme positive reaction all of them showed marked improvement on removing the offending agent.

DISCUSSION: A patch testis a method used to determine whether a specific substance causes allergic inflammation of a patient's skin. Any individual suspected of having allergic contact dermatitis and/or atopic dermatitis needs patch testing.

Patch test may help to identify the substances which may cause a delayed-type allergic reaction in a patient, and may identify allergens which are not identified by blood test or skin prick test. It is intended to produce a local allergic reaction on a small area of the patient's back, where the diluted chemicals are planted. The chemicals included in the patch test kit are the offenders in approximately 85-90 percent of allergic contact eczema, and include chemicals present in metals (e.g., nickel), rubber, leather, formaldehyde, lanolin, fragrance, toiletries, hair dyes, medicine, pharmaceutical items, food, drink, preservative, and other additives. A patch test relies on the principle of a type IV hypersensitivity reaction.

The top allergens from 2005-06 were: nickel sulfate (19.0\%), Myroxylonpereirae (Balsam of Peru, 11.9\%), fragrance mix I (11.5\%), quaternium-15 (10.3\%), neomycin $(10.0 \%)$, bacitracin $(9.2 \%)$, formaldehyde (9.0\%), cobalt chloride (8.4\%), methyldibromoglutaronitrile/phenoxyethanol (5.8\%), p-phenylenediamine $(5.0 \%)$, potassium dichromate $(4.8 \%)$, carba mix $(3.9 \%)$, thiuram mix $(3.9 \%)$, diazolidinyl urea (3.7\%), and 2-bromo-2-nitropropane-1, 3-diol (3.4\%). ${ }^{1}$ Our study showed that the most common allergen were nickel sulphate (14.2\%), colphony (14.2\%), potassium dichromate (11.9\%), cobalt sulphate(9.5\%), chlorocresol, black rubber(7.1\%), fragrance, parthenium. Paraphenyldiamine, formaldehyde, mercaptobenzene, nitrofurazon, benzocaine, thiuram mix (4.7\%), neomycin, wool alcohol, epoxy resin $(2.3 \%)$.

The most frequent allergen recorded in many research studies around the world is nickel. It is naturally present in food like green leafy vegetables, eggs, meat and milk. The metal is hard, strong, and silvery white in color, resist corrosion and can be polished to give a bright gloss. All these properties make it ideal for making household equipment and jewelry, and for use in wearing apparel and industry. Among females the contact allergy due to nickel general population is around $10 \%{ }^{2}$ and is on the rise. ${ }^{3}$ Today ear piercing is the principal inducer of nickel hypersensitivity. ${ }^{4}$ Our study showed equal prevalence of nickel sensitivity in males and females and all of them had hand eczema. Colophony is present as a tackifier in shoe dermatitis. It is mostly found in adhesive tapes, insulating tape, scotch tape, polish, paints, inks, glossy paper. Potassium dichromate is a hexavalent chromium compound. Chromium has been reported to be the most common allergen in Israel ${ }^{5}$, India, ${ }^{6}$ Italy $^{7}$ and Greece. ${ }^{8}$ In India it accounts for almost $75 \%$ of all cases of shoe dermatitis and there was not even a single patient allergic to vegetable tannin. ${ }^{8}$ Cobalt dermatitis may occur in those individuals who are involved in manufacture of polyester resins and paints, hard metals used for cutting and drilling tools and the manufacture and use of cement. Cobalt is a contaminant of cement so in cement dermatitis, sensitivity to cobalt as well as to chromate may occur ${ }^{9}$.Cholrocrescol is an efficient bactericide used 
as a preservative. It has a low sensitizing potential and is an infrequent sensitizer. ${ }^{10}$ Black rubber mix is a mixture of three compound $\mathrm{N}$-isopropyl-N-phenyl paraphenylenediamine, N-Cyclohexyl- $\mathrm{N}$ Phenyl paraphenylenediamine and N-N-Diphenyl paraphenyl lenediamine. It is found in natural rubber, styrene-butadiene and chloroprene rubber. Rubber gloves are considered to be the main source of sensitization by many authors. ${ }^{11}$

Other objects such as condoms, shoes, boots, underwear elastics and belts are also important. ${ }^{12,13}$ Fragnance are found in perfumes, deodorants, insect attractants, toothpaste and soft drinks. Parthenium hyterophorus is a weed from the composite family. In India parthenium is the most notorious weed known to produce contact dermatitis. The first case of contact hypersensitivity to parthenium in India was recorded from Pune in 196814.Paraphenyldiamine is found in hair dyes, fur dyes, leather processing, rubber vulcanizing, printing, photography work, and X ray fluids. It can cross react with other dyes like Azo and aniline dyes, procaine, benzocaine, PABA, and sulfonamides. Formaldehyde is found in shampoos, antiperspirants, deodorants, nail hardeners, nail polish, soaps, wart remedies, fungicides, insecticides, gums, leather, rubber and adhesives.

Mercaptobenzene and thiuram mix are used as adhesives in linings and inner socks of shoes. In Bajaj et al's series, 14 out of 102 patients' cases were positive to mercaptobenzene ${ }^{8}$.Our study showed total 3 patients out of 70 patients positive to mercaptobenzene. Nitrofurazone was a common sensitizer in India ${ }^{15}$ but the incidence has reduced ${ }^{16}$ due to infrequent use. Neomycin is a known potent sensitizer all over the world. The reported incidence varies from $2.5 \%-6 \%$ and even more. ${ }^{9}$, 17,18 In India the reported incidence is much higher due to its testing in selected group of patients rather than routine testing in all patients. ${ }^{16,19}$

CONCLUSION: Patch test is the method of choice and the "gold standard" in the detection of contact allergy and allergic contact dermatitis. Their execution increases the probability of correct diagnosis, shortens the time lapse between first visit and final diagnosis, increases the chance for full remission, and reduces therapy costs. Altogether, patch tests help in improving patients' quality of life. The application of patch tests in not difficult, however, correct interpretation of the results requires appropriate training and experience.

\section{REFERENCES:}

1. Zug KA, Warshaw EM, Fowler JF Jr, Maibach HI, Belsito DL, Pratt MD, Sasseville D, Storrs FJ, Taylor JS, Mathias CG, Deleo VA, Rietschel RL, Marks J. Patch-test results of the North American Contact Dermatitis Group 2005-2006. Dermatitis. 2009 May-Jun; 20(3): 149-60.

2. Peltonen L. Nickel sensitivity in the general population. Contact Dermatitis.1979; 5: 27-32.

3. Edman B, Moller $\mathrm{H}$. Trends and forecasts for standard allergens in a 12 year patch test material.1982; 8: 95-104

4. Stadeler J. Uber die eigen Thumlichen Best and theile der Anacardium Fruchte. Ann chemie Pharamacie. 1847; 63: 117-165.

5. Collins EJ. Atropine irritation. R Lond Opthal Hosp Rep. 1989; 12: 164.

6. Jadassohn J. Zurkenntnis der medicamentosen Dermatosenverhandlingen der Deutschen Dermalologishen Gesellschaft, V Congress, Wien.(1895): 103-129.

7. Landsteiner K, Jacobs J. Studies on the sensitization of animals with simple chemical compounds: II. J Exp Med.1935; 61: 625-639

8. Bajaj AK, Gupta SC, Chatterjee AK, Singh KG. Shoe dermatitis in India: Further observations. Contact Dermatitis.1991; 24: 149-51 
9. Goh CL, Gan SL, Ngui SJ. Occupational dermatitis in a prefabrication construction factory. Contact dermatitis.1986; 15: 235-240

10. Burry JN, Kirk J, Reid JG, Turner T. Chlorocresol sensitivity. Contact Dermatitis.1975; 1; 41-72

11. Estlander T, Jolanki R, Kanerva L. Dermatitis and urticaria from rubber and plastic gloves. Contact Dermatitis. 1986; 14: 20-25

12. Leider M, Furman D, Fisher AA, Sensitivity to rubber materials. Arch Dermatol Syph.1952; 65587-95

13. Wilson HTH. Rubber glove dermatitis.Br Med J. 1960; 2: 21-23

14. Lonkar A, Jog MK. Dermatitis caused by a plant partheniumhysterophorus. Indian J Dermatol Venereol Leprol.1968; 34: 194-96.

15. Bajaj AK, Gupta SC. Contact hypersensitivity to topical antimicrobials agents. Int J Dermatol.1986; 25: 103-105.

16. George ND, Srinivas CR, Balachandran C, Shenoi SD. Sensitivity to various, ingredients of topical preparations following prolonged use. Contact Dermatitis. 1990; 23: 367-368.

17. Nethercott JR. Results of routine patch testing of 200 patients in Toronto, Canada. Contact Dermatitis.1982; 8: 389-395.

18. Rudner E, Clendenning WE, Epstein E, et al. Epidemiology of contact dermatitis in North America. Arch Dermatol.1973; 108: 537-540.

19. Kaur S, Sharma VK. Indigenous patch test unit resembling Finn Chamber. Indian J Dermatol Venereol Leprol.1986; 52: 332336.

\section{AUTHORS:}

1. Shifa Yadav

2. Dinesh Mathur

3. Manisha Nijhawan

4. Savita Agrawal

5. Aakansha Singh

6. Vibhor Goyal

7. Shilpa Soni

8. Rakesh Jangra

\section{PARTICULARS OF CONTRIBUTORS:}

1. $2^{\text {nd }}$ Year Resident, Department of Dermatology, Venereology and Leprosy, Mahatma Gandhi Hospital, Sippula, Jaipur, Rajasthan.

2. Head of the Department, Department of Dermatology, Venereology and Leprosy, Mahatma Gandhi Hospital, Sippula, Jaipur,

3. Professor, Department of Dermatology, Venereology and Leprosy, Mahatma Gandhi Hospital, Sippula, Jaipur,

4. Senior Resident, Department of Dermatology, Venereology and Leprosy, Mahatma Gandhi Hospital, Sippula, Jaipur,
5. $\quad 2^{\text {nd }}$ Year Resident, Department of Dermatology, Venereology and Leprosy, Mahatma Gandhi Hospital, Sippula, Jaipur,

6. $1^{\text {st }}$ Year Resident, Department of Dermatology, Venereology and Leprosy, Mahatma Gandhi Hospital, Sippula, Jaipur,

7. $1^{\text {st }}$ Year Resident, Department of Dermatology, Venereology and Leprosy, Mahatma Gandhi Hospital, Sippula, Jaipur,

8. $1^{\text {st }}$ Year Resident, Department of Dermatology, Venereology and Leprosy, Mahatma Gandhi Hospital, Sippula, Jaipur,

\section{NAME ADDRESS EMAIL ID OF THE CORRESPONDING AUTHOR:}

Dr. Shifa Yadav,

Room No. -12, Type IV-A Building,

Old PG Hostel, Mahatma Gandhi Hospital, Jaipur.

Email: shifayadav@gmail.com

Date of Submission: 04/09/2014.

Date of Peer Review: 05/09/2014.

Date of Acceptance: 09/09/2014.

Date of Publishing: 13/09/2014. 